\title{
Effects of Plant Extracts on Dentin Bonding Strength: A Systematic Review and Meta-Analysis
}

\begin{abstract}
Shikai Zhao ${ }^{1 \dagger}$, Fang Hua ${ }^{2,3+}$, Jiarong Yan ${ }^{1}$, Hongye Yang ${ }^{1,4 *}$ and Cui Huang ${ }^{1,4 *}$
${ }^{1}$ The State Key Laboratory Breeding Base of Basic Science of Stomatology (Hubei-MOST) and Key Laboratory for Oral Biomedical Ministry of Education, School and Hospital of Stomatology, Wuhan University, Wuhan, China, ${ }^{2}$ Department of Orthodontics, Center for Evidence-Based Stomatology, School and Hospital of Stomatology, Wuhan University, Wuhan, China, ${ }^{3}$ Division of Dentistry, School of Medical Sciences, Faculty of Biology, Medicine and Health, Manchester Academic Health Science Centre, University of Manchester, Manchester, United Kingdom, ${ }^{4}$ Department of Prosthodontics, School and Hospital of Stomatology, Wuhan University, Wuhan, China
\end{abstract}

Objective: To systematically review in vitro studies that evaluated the effects of plant extracts on dentin bonding strength.

OPEN ACCESS

Edited by:

Kumar Chandan Srivastava, Al Jouf University, Saudi Arabia

Reviewed by: Monica Yamauti, Hokkaido University, Japan Joanna Mystkowska, Bialystok University of Technology, Poland

*Correspondence: Hongye Yang yanghongye@whu.edu.cn Cui Huang

huangcui@whu.edu.cn

${ }^{+}$These authors have contributed equally to this work

Specialty section: This article was submitted to Biomaterials,

a section of the journal Frontiers in Bioengineering and

Biotechnology

Received: 15 December 2021 Accepted: 31 January 2022 Published: 24 February 2022

Citation:

Zhao S, Hua F, Yan J, Yang $H$ and Huang C (2022) Effects of Plant Extracts on Dentin Bonding Strength: A Systematic Review and Meta-

Analysis.

Front. Bioeng. Biotechnol. 10:836042. doi: 10.3389/fbioe.2022.836042
Materials and Methods: Six electronic databases (PubMed, Embase, VIP, CNKI, Wanfang and The Cochrane Library) were searched from inception to September 2021 in accordance with the Preferred Reporting Items for Systematic Reviews (PRISMA). In vitro studies that compared the performance of dental adhesives with and without the plant extracts participation were included. The reference lists of the included studies were manually searched. Two researchers carried out study screening, data extraction and risk of bias assessment, independently and in duplicate. Meta-analysis was conducted using Review Manager 5.3.

Results: A total of 62 studies were selected for full-text analysis. 25 articles used the plant extracts as primers, while five added the plant extracts into adhesives. The meta-analysis included 14 articles of in vitro studies investigating the effects of different plant extract primers on dentin bonding strength of etch-and-rinse and self-etch adhesives, respectively. The global analysis showed statistically significant difference between dental adhesives with and without plant extract primers. It showed that the immediate bond strength of dental adhesives was improved with the application of plant extract primers.

Conclusion: The application of proanthocyanidin (PA) primers have positive effect on the in vitro immediate bonding strength of dental adhesives irrespective of etch-and-rinse or self-etch modes.

Keywords: dentin, bonding, plant extracts, natural crosslinkers, adhesives, primers

\section{INTRODUCTION}

Dentin bonding is the foundation of esthetic restoration (Drummond, 2008). Nowadays, manufacturers claim that dental adhesive system has already developed to the eighth generation (Taneja et al., 2017). However, irrespective of acceptable immediate bonds, the long-term bonding strength of these adhesives is inadequate (Deligeorgi et al., 2001; Hass et al., 2016a). As a result, nearly half of esthetic restorations cannot serve for more than 10 years, and dentists have to spend $60 \%$ of 
working hours to replace them (Mjor et al., 2000; Deligeorgi et al., 2001). Thus, the improvement of long-term bond strength is still a puzzle that needs to be solved.

Unsatisfactory long-term dentin bonds are usually attributed to two reasons: The degradation of dentin collagen within the hybrid layer; and the emergence of secondary caries at the interface (Brackett et al., 2011). A reasonable strategy to solve these problems is to modify contemporary dental adhesives with different additives, such as chlorhexidine, nano-silver, carbon nanotube and amorphous calcium phosphate (Carrilho et al., 2007; Borges et al., 2013; Zhang et al., 2013; Alkatheeri et al., 2015). Amongst these additives, plant extracts attracted great attention due to their biological safety and functional versatility (Gotti et al., 2015; Yang et al., 2017; Yu et al., 2017). Many articles have reported the advantages of natural plant extracts, including their capability to stabilize dentin collagen (La et al., 2009), and to inhibit MMPs (Du et al., 2012; Yang et al., 2016) and microbes (Kaul et al., 1985; Rigano et al., 2007). Therefore, many researchers have been attempting to dope plant extracts into adhesives or provide a separate plant extract primer to achieve high antibiotic property and improved long-term bond strength (La et al., 2009; Borges et al., 2013; Gotti et al., 2015; Yang et al., 2017).

However, the combination of different adhesives with different plant extracts may produce unpredictable results, and different concentration of plant extract primer may have different bonding performance (Macedo et al., 2009; Islam et al., 2014). Previous studies have tested a limited amount of plant extracts, using different experimental designs, with contradictory conclusions. Thus, a comprehensive overview summarizing the effect of all existing plant extracts on dental adhesives will be helpful for dental clinicians and relevant researchers.

The objectives of this study are to systematically review the in vitro studies that evaluated adhesive-dentin bond strength with or without plant extracts participation and to compare different plant extracts in terms of bond strength. The hypotheses are: no difference exists in the bond strengths when modifying the adhesives with plant extracts; no difference exists in the bond strengths when plant extract primers are used; no difference exists in the bond strength when using different concentrations of plant extracts.

\section{MATERIALS AND METHODS}

\section{Criteria for Considering Studies for This Review \\ Inclusion Criteria}

- Studies that added plant extracts to dental adhesives or used plant extract as primers.

- Studies that compared the performance of dental adhesives with and without the participation of plant extracts.

- In vitro studies that evaluated the bond strength of dental adhesives.

\section{Exclusion criteria}

Reviews, clinical trials or case reports.

\section{Search Strategy}

A systematic electronic search was conducted by two independent reviewers (SZ and HY) using nine databases (PubMed, Embase, Web of Science, Cochrane Library, VIP, CNKI, Wanfang, OpenGrey literature and ProQuest Dissertation Abstracts) from inception to September 2021 to identify articles related to plant extracts and dental bonding. The search terms were a combination of subject terms and free-text terms (Appendix Table A1).

When multiple publications about the same intervention were identified, the most informative and relevant article was selected for inclusion.

\section{Data Collection and Analysis Selection of Studies}

Article titles and abstracts were independently screened by two authors (SZ and HY). The authors conducted a second review when the inclusion criteria were met. The abstracts were examined by two review authors (SZ and HY) independently using the same inclusion criteria. If there were disagreements, the abstract would be assessed by the third author (FH). Then full text of all potentially relevant studies were retrieved and independently assessed in duplicate by two review authors (SZ and HY). Any disagreement regarding the eligibility of the included studies was resolved through discussion with the third reviewer.

\section{Data Extraction and Management}

Data extraction was performed independently by two authors (SZ and HY). The demographic data, plant extracts used, plant extract concentration, bonding systems, as well as outcomes were recorded (Table 1). If any information was missing, we contacted the corresponding authors via email.

\section{Quality Assessment}

Two reviewers (SZ and HY) independently assessed the risk of bias of the included studies with the assessment instrument used in a previous systematic review of in vitro studies (Sarkis-Onofre et al., 2014). Quality assessment parameters included randomized teeth, teeth free of caries or restoration, operation following the manufacturer's instructions, given sample size, and the bonding procedures were performed by a single operator with or without blinding. The article would be given a "Yes" on the parameter if it was reported and performed appropriately in the article; and a "No" if it was not mentioned or not performed properly. Articles were classified into three levels of risk of bias according to the number of parameters that scored "Yes": high ( $\leq 2$ parameters), medium (3-4 parameters), and low (5-6 parameters) (Table 2).

\section{Statistical Analysis}

Meta-analysis was conducted using Review Manager 5.3. Each possible comparison of the bond strength of dental adhesives with or without plant extracts participation was undertaken. In order to minimize the heterogeneity, only in vitro studies comparing the same plant extracts with the same concentration was included 
TABLE 1 | Characteristics of the included studies.

\begin{tabular}{|c|c|c|c|c|c|c|c|c|}
\hline $\begin{array}{l}\text { First } \\
\text { author }\end{array}$ & Year & Country & Publication & $\begin{array}{c}\text { Plant } \\
\text { extracts }\end{array}$ & $\begin{array}{l}\text { Action } \\
\text { modes }\end{array}$ & $\begin{array}{c}\text { Plant } \\
\text { extracts } \\
\text { concentration }\end{array}$ & $\begin{array}{c}\text { Dental } \\
\text { adhesives }\end{array}$ & Outome \\
\hline $\begin{array}{l}\text { Albuquerque } \\
\mathrm{N}\end{array}$ & 2019 & Brazil & Oper Dent & EGCG & Adhesive & $0.1 \% \mathrm{w} / \mathrm{v}$ & $\begin{array}{l}\text { Single Bond } 2 \text { (3M ESPE, St. } \\
\text { Paul, MN, United States) }\end{array}$ & MTBS \\
\hline Yang $\mathrm{H}$ & 2017 & China & SCI REP & Quercetin & Adhesive & 100,500 and $1,000 \mu \mathrm{g} / \mathrm{ml}$ & Single Bond 2 & MTBS \\
\hline $\mathrm{YuHH}$ & 2017 & China & $\begin{array}{l}\text { Materials } \\
\text { (Basel) }\end{array}$ & EGCG, EGCG-3Me & Adhesive & 200,400, and $600 \mu \mathrm{g} / \mathrm{ml}$ & Single Bond 2 & MTBS \\
\hline Gotti VB & 2015 & Brazil & J Adhes Dent & Quercetin & Adhesive & $5 w t \%$ & $\begin{array}{l}\text { Single Bond 2; Clearfil SE } \\
\text { Bond (Kurary Noritake } \\
\text { Dental; Tokyo, Japan); Easy } \\
\text { Bond (3M ESPE, St. Paul, } \\
\text { MN, United States) }\end{array}$ & MTBS \\
\hline Du X & 2012 & China & J Dent & EGCG & Adhesive & 100,200 , and $300 \mu \mathrm{g} / \mathrm{ml}$ & Single Bond 2 & MTBS \\
\hline Peng W & 2020 & China & $\begin{array}{l}\text { Materials } \\
\text { Science and } \\
\text { Engineering } \mathrm{C}\end{array}$ & Resveratrol & Primer & 1,10 , and $20 \mu \mathrm{g} / \mathrm{ml}$ & Single Bond Universal & MTBS \\
\hline Zhang Z & 2020 & China & $\begin{array}{l}\text { Dental } \\
\text { Materials }\end{array}$ & EGCG & Primer & $0.01 \%, 0.1 \%, 1 \%$ & Single Bond Universal & MTBS \\
\hline Landmayer K & 2020 & Brazil & J Prosthet Dent & $\begin{array}{l}\text { EGCG; } \\
\text { Proanthocyanidin (PA) }\end{array}$ & Primer & EGCG at $400 \mu \mathrm{M} ; 10 \%$ PA & Single Bond 2 & MTBS \\
\hline $\begin{array}{l}\text { Dávila- } \\
\text { Sánchez A }\end{array}$ & 2020 & Chile & Dent Mater & $\begin{array}{l}\text { Quercetin; Hesperidin; } \\
\text { Rutin; Naringin; } \\
\text { Proanthocyanidin }\end{array}$ & Primer & 0.065 & Single Bond Universal & MTBS \\
\hline $\begin{array}{l}\text { de } \\
\text { Siqueira FSF }\end{array}$ & 2020 & Brazil & $\begin{array}{l}\text { Clin Oral } \\
\text { Investig }\end{array}$ & Proanthocyanidin & Primer & 0.065 & $\begin{array}{l}\text { Prime and Bond Elect } \\
\text { (Dentsply Sirona, Milford, } \\
\text { DE, United States); Single } \\
\text { Bond Universal; Tetric } \\
\text { n-Bond Universal (Ivoclar } \\
\text { Vivadent AG, Schaan, } \\
\text { Liechtenstein) }\end{array}$ & MTBS \\
\hline Yi L & 2019 & China & J Dent & Baicalein & Primer & $0.01 \%, 0.05 \%$, and $1 \% \mathrm{w} / \mathrm{v}$ & Single Bond Universal & MTBS \\
\hline $\begin{array}{l}\text { Albuquerque } \\
\mathrm{N}\end{array}$ & 2019 & Brazil & Oper Dent & EGCG & Primer & $\begin{array}{l}0.1 \% \text { EGCG; or 1\% PLGA } \\
\text { EGCG }\end{array}$ & Single Bond 2 & MTBS \\
\hline Costa CAG & 2019 & Brazil & $J$ Adhes Dent & EGCG & Primer & $0.1 \%$ EGCG; or $2 \%$ CHX & Clearfil SE Bond & MTBS \\
\hline Fialho MPN & 2019 & Brazil & $\begin{array}{l}\text { J Mech Behav } \\
\text { Biomed Mater }\end{array}$ & EGCG & Primer & $0.02 \% ; 0.2 \% ; 0.5 \%$ & Single Bond 2 & MTBS \\
\hline Li J & 2018 & China & Oper Dent & Baicalein & Primer & $0.1,0.5,2.5$, and $5.0 \mu \mathrm{g} / \mathrm{ml}$ & Single Bond 2 & MTBS \\
\hline Porto ICCM & 2018 & Brazil & Eur J Oral Sci & Quercetin; Resveratrol & Primer & $\begin{array}{l}100,250,500 \text {, or } \\
1,000 \mu \mathrm{g} \mathrm{ml} \text {, a mixture of } \\
\text { quercetin and resveratrol (3: } \\
1,1: 1,1: 3 ; \text { vol:vol }\end{array}$ & Single Bond Universal & MTBS \\
\hline Bacelar-Sá R & 2017 & Brazil & Braz Dent J & Proanthocyanidin & Primer & 0.065 & $\begin{array}{l}\text { Single Bond Universal; } \\
\text { Prime and Bond Elect; All- } \\
\text { Bond } 3 \text { (Bisco Inc., } \\
\text { Schaumburg, IL, } \\
\text { United States); G-Aenial (GC } \\
\text { Corp., Tokyo, Japan) }\end{array}$ & MTBS \\
\hline LiK & 2017 & China & RSC Adv & Quercetin & Primer & $0.1,0.5$, and $1 w t \%$ & Single Bond 2 & MTBS \\
\hline Zheng P & 2017 & China & Sci Rep & Proanthocyanidin & Primer & 0.05 & Single Bond 2 & MTBS \\
\hline Zhou J & 2016 & China & Dent Mater & Grape seed extract & Primer & 5 mass $\%$ & Single Bond 2 & MTBS \\
\hline Hass V & 2016 & Brazil & Dent Mater & Proanthocyanidin & Primer & $6.5 w t \%$ & $\begin{array}{l}\text { Single Bond Plus; Tetric } \\
\text { N-Bond }\end{array}$ & MTBS \\
\hline Yang $\mathrm{H}$ & 2016 & United States & J Dent & EGCG & Primer & $0.02 \%$ and $0.1 \%$ & Single Bond 2 & MTBS \\
\hline Zheng P & 2015 & China & Oper Dent & Grape seed extract & Primer & 0.0005 & $\begin{array}{l}\text { OptiBond FL (Kerr, Scafati, } \\
\text { Italy); Clearfil SE Bond }\end{array}$ & MTBS \\
\hline Islam MS & 2014 & Japan & Dent Mater & $\begin{array}{l}\text { Proanthocyanidin; } \\
\text { Hesperidin }\end{array}$ & Primer & $\begin{array}{l}0.5 \%, 1 \%, 2 \%, 5 \% \text { of } \\
\text { hesperidin (HPN) or } 0.5 \% \text { of } \\
\text { proanthocyanidins (PA) }\end{array}$ & Clearfil SE Bond & MTBS \\
\hline Liu RR & 2014 & China & Int J Oral Sci & Proanthocyanidin & Primer & $10 \%$ or $15 \%$ & Single Bond 2 & MTBS \\
\hline Santiago SL & 2013 & Brazil & $J$ Adhes Dent & EGCG & Primer & $0.02 \%, 0.1 \%$, or $0.5 \%$ w/v & Single Bond 2 & MTBS \\
\hline Broyles AC & 2013 & United States & J Prosthodont & Grape seed extract & Primer & 0.065 & $\begin{array}{l}\text { RelyX Unicem (3M ESPE, St. } \\
\text { Paul, MN, United States); } \\
\text { G-Cem self-adhesive } \\
\text { cements (GC America, } \\
\text { Alsip, IL) }\end{array}$ & MTBS \\
\hline
\end{tabular}

(Continued on following page) 
TABLE 1 | (Continued) Characteristics of the included studies.

\begin{tabular}{|c|c|c|c|c|c|c|c|c|}
\hline $\begin{array}{l}\text { First } \\
\text { author }\end{array}$ & Year & Country & Publication & $\begin{array}{c}\text { Plant } \\
\text { extracts }\end{array}$ & $\begin{array}{l}\text { Action } \\
\text { modes }\end{array}$ & $\begin{array}{c}\text { Plant } \\
\text { extracts } \\
\text { concentration }\end{array}$ & $\begin{array}{c}\text { Dental } \\
\text { adhesives }\end{array}$ & Outome \\
\hline Liu RR & 2012 & China & $\begin{array}{l}\text { Zhonghua Kou } \\
\text { Qiang Yi Xue } \\
\text { Za Zhi }\end{array}$ & Proanthocyanidin & Primer & 0.15 & Single Bond 2 & MTBS \\
\hline Macedo GV & 2009 & United States & J Dent Res & Grape seed extract & Primer & 0.065 & $\begin{array}{l}\text { Single Bond 2; One Step } \\
\text { Plus (Bisco, Schaumburg, } \\
\text { IL, United States) }\end{array}$ & MTBS \\
\hline Al-Ammar A & 2009 & United States & $\begin{array}{l}\text { J Biomed Mater } \\
\text { Res B Appl } \\
\text { Biomater }\end{array}$ & $\begin{array}{l}\text { Grape seed extract; } \\
\text { Genipin }\end{array}$ & Primer & 6.5\% GSE; 0.5\% GE & $\begin{array}{l}\text { One Step Plus; Single Bond } \\
\text { Plus }\end{array}$ & MTBS \\
\hline
\end{tabular}

Abbreviation: EGCG, epigallocatechin-3-gallate; EGCG-3Me, epigallocatechin-3-O-(3-O-methyl)-gallate; GSE, grape seed extract; GE, genipin.

TABLE 2 | Risk of bias of the studies considering aspects reported in the Materials and Methods section.

\begin{tabular}{|c|c|c|c|c|c|c|c|c|}
\hline Study & Year & Random & Caries & Adhesive & Sample & Operator & Blind & Risk \\
\hline Peng W & 2020 & Y & $Y$ & $Y$ & $Y$ & Y & $\mathrm{N}$ & Low \\
\hline Zhang Z & 2020 & $Y$ & $\mathrm{~N}$ & $Y$ & Y & $Y$ & $\mathrm{~N}$ & Medium \\
\hline Landmayer K & 2020 & $\mathrm{~N}$ & Y & $Y$ & Y & $\mathrm{N}$ & $\mathrm{N}$ & Medium \\
\hline Dávila-Sánchez A & 2020 & Y & Y & Y & Y & Y & $\mathrm{N}$ & Low \\
\hline de Siqueira FSF & 2020 & Y & Y & Y & Y & Y & $\mathrm{N}$ & Low \\
\hline Albuquerque $\mathrm{N}$ & 2019 & Y & Y & Y & Y & $\mathrm{N}$ & $\mathrm{N}$ & Medium \\
\hline Yi L & 2019 & Y & Y & Y & Y & $Y$ & $\mathrm{~N}$ & Low \\
\hline Albuquerque $\mathrm{N}$ & 2019 & $\mathrm{~N}$ & Y & Y & Y & $\mathrm{N}$ & $\mathrm{N}$ & Medium \\
\hline Costa CAG & 2019 & Y & Y & Y & $Y$ & $\mathrm{~N}$ & $\mathrm{~N}$ & Medium \\
\hline Fialho MPN & 2019 & $N$ & Y & Y & $Y$ & $Y$ & $\mathrm{~N}$ & Medium \\
\hline Li J & 2018 & $Y$ & Y & Y & Y & $\mathrm{N}$ & $\mathrm{N}$ & Medium \\
\hline Porto ICCM & 2018 & Y & Y & Y & Y & $\mathrm{N}$ & $\mathrm{N}$ & Medium \\
\hline Yang H & 2017 & $Y$ & Y & $Y$ & $Y$ & $\mathrm{~N}$ & $\mathrm{~N}$ & Medium \\
\hline Yu HH & 2017 & Y & Y & $Y$ & Y & $\mathrm{N}$ & $\mathrm{N}$ & Medium \\
\hline Bacelar-Sá R & 2017 & $\mathrm{~N}$ & Y & $Y$ & $Y$ & $\mathrm{~N}$ & $\mathrm{~N}$ & Medium \\
\hline LiK & 2017 & $Y$ & Y & $Y$ & $Y$ & $\mathrm{~N}$ & $\mathrm{~N}$ & Medium \\
\hline Zheng P & 2017 & $\mathrm{~N}$ & Y & $Y$ & $Y$ & $\mathrm{~N}$ & $\mathrm{~N}$ & Medium \\
\hline Zhou J & 2016 & $\mathrm{~N}$ & $Y$ & $Y$ & $Y$ & $\mathrm{~N}$ & $\mathrm{~N}$ & Medium \\
\hline Hass V & 2016 & $\mathrm{~N}$ & Y & $Y$ & $Y$ & $\mathrm{~N}$ & $\mathrm{~N}$ & Medium \\
\hline Yang $\mathrm{H}$ & 2016 & $\mathrm{~N}$ & $Y$ & $Y$ & $Y$ & $Y$ & $\mathrm{~N}$ & Medium \\
\hline Gotti VB & 2015 & $Y$ & $N$ & Y & $Y$ & $N$ & $\mathrm{~N}$ & Medium \\
\hline Zheng P & 2015 & $Y$ & Y & $Y$ & $Y$ & $\mathrm{~N}$ & $\mathrm{~N}$ & Medium \\
\hline Islam MS & 2014 & $\mathrm{~N}$ & Y & Y & Y & $\mathrm{N}$ & $\mathrm{N}$ & Medium \\
\hline Liu RR & 2014 & $Y$ & Y & $Y$ & $Y$ & $\mathrm{~N}$ & $\mathrm{~N}$ & Medium \\
\hline Santiago SL & 2013 & $\mathrm{~N}$ & $Y$ & $Y$ & $Y$ & $\mathrm{~N}$ & $\mathrm{~N}$ & Medium \\
\hline Broyles AC & 2013 & $Y$ & Y & $Y$ & $Y$ & $\mathrm{~N}$ & $\mathrm{~N}$ & Medium \\
\hline Du X & 2012 & $Y$ & $\mathrm{~N}$ & $Y$ & $Y$ & $\mathrm{~N}$ & $\mathrm{~N}$ & Medium \\
\hline Liu RR & 2012 & Y & Y & Y & $Y$ & $\mathrm{~N}$ & $\mathrm{~N}$ & Medium \\
\hline Macedo GV & 2009 & $Y$ & Y & $Y$ & $Y$ & $\mathrm{~N}$ & $\mathrm{~N}$ & Medium \\
\hline Al-Ammar A & 2009 & $Y$ & $Y$ & $Y$ & $Y$ & $\mathrm{~N}$ & $N$ & Medium \\
\hline
\end{tabular}

in the global analysis. The mean difference with $95 \%$ confidence interval (CI) was calculated and $p \leq 0.05$ was considered significant. Statistical heterogeneity was assessed using the modified chi-square test (Cochran's Q), which indicates heterogeneity when $\mathrm{p}>0.1$, and $\mathrm{I}^{2}$ test, which indicates heterogeneity when its values is greater than $50 \%$. Randomeffect model was used in the analysis. The publication bias was to be assessed if more than ten studies were included in a meta-analysis. Sensitivity analysis was also performed by sequentially excluding each study if there were sufficient studies $(\geq 10)$.

\section{RESULTS}

\section{Search Strategy and Characteristics}

The initial search yielded 341 articles, out of which, 36 articles were eliminated after screening of titles and removal of duplicates. After abstract screening, 243 articles were excluded. A resultant sample of 62 articles was carried forward to the next stage, in which full-text copies were scrutinized. Finally, a total of 30 studies were systematically reviewed, in which 5 studies added plant extracts into adhesives and 25 studies used plant extract solution as primers (Figure 1). Twenty-nine articles were in 


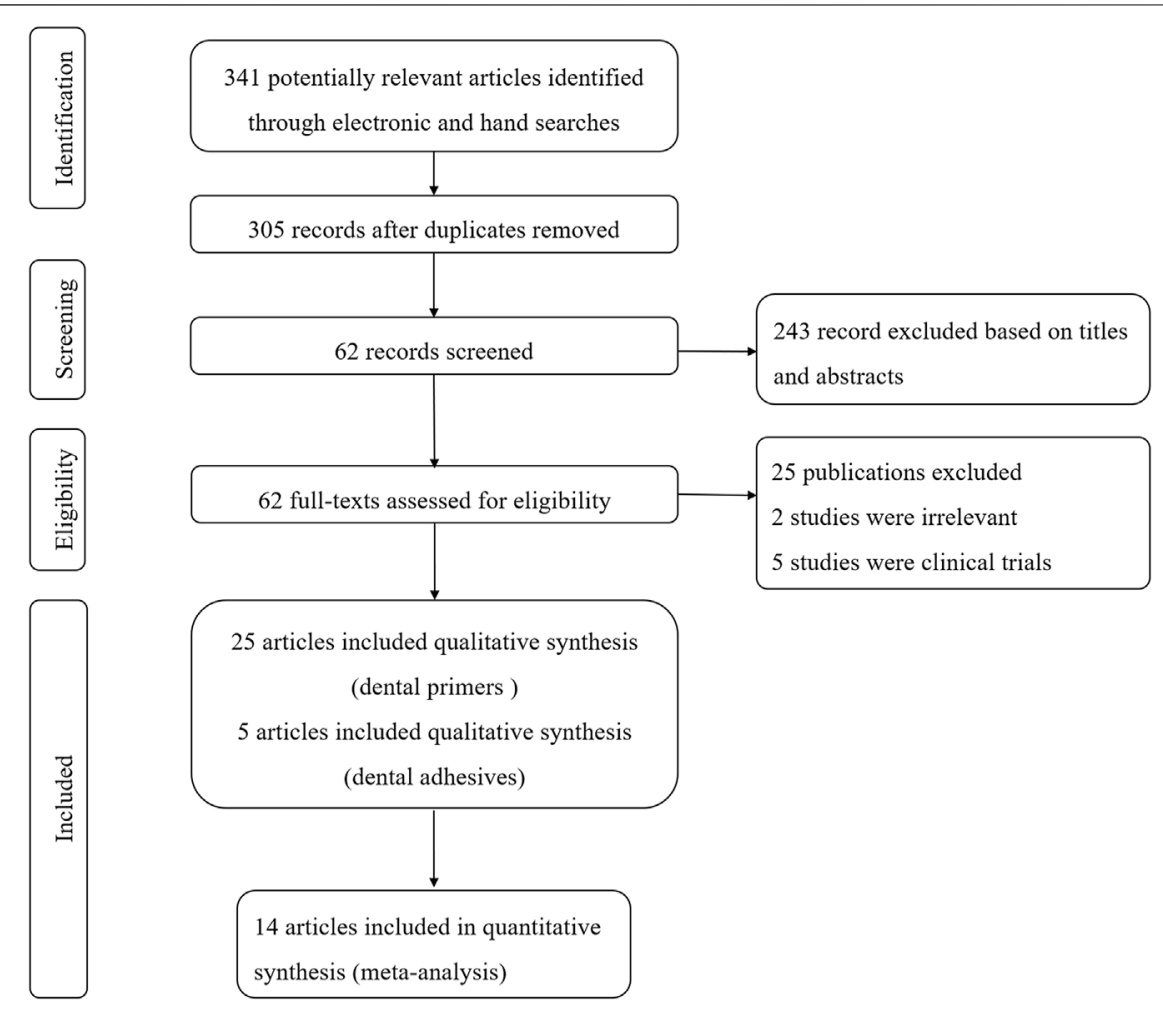

FIGURE 1 | Flow chart of study selection according to PRISMA statement.

English and 1 were in Chinese. There are nine types of plant extracts and 15 types of adhesives involved (Table 1).

\section{Risk of Bias}

Most of the 30 studies (86.7\%) exhibited a medium risk of bias, except for four (13.3\%) with a low risk of bias. All of the studies used the adhesive according to the manufacturer's instructions and described sample size calculation, but none of the studies reported blinding. A total of 20 studies (66.7\%) reported random assignment of teeth, and 27 studies (90\%) used teeth free of caries. Only seven studies (23.3\%) reported adhesive procedure performed by a single operator. The results are described in Figure 2 and Table 2.

\section{Meta-Analysis}

In the studies included in the meta-analysis, we only choose the data of interest. Only commercial adhesives were included, and the studies used experimental adhesives were excluded (Epasinghe et al., 2012). The effect of plant extracts on bonding strength may be related to different bonding modes such as self-etch or etch-and-rinse (Macedo et al., 2009; Bacelar-Sa et al., 2017). Hence, the disparity of the bond strength of different plant extracts in selfetch or etch-and-rinse adhesives was compared. Because aging methods were highly heterogeneous (i.e., water storage, saliva storage and $\mathrm{PH}$ cycling), it was not considered in the metaanalysis (Deng et al., 2014).

Due to the fact that different concentrations of plant extracts were used, only those with the same concentration were taken into meta-analysis. Of the 30 studies, data from 14 papers in which plant extract solution serve as primers underwent meta-analysis. The results of the meta-analysis are shown in Figures 3-5.

\section{Etch-and-Rinse Bond Strength (Plant Extract Primers)}

The first analysis (etch-and rinse adhesive with or without plant extract primers) was performed, and the different concentration of plant extracts were the subgroups. A total of 29 datasets were selected, while 14 studies were included (Figure 3), with the following results: Q-test $p<0.00001, \mathrm{I}^{2}=95 \%$ and overall effect $p=0.0007$. Test for subgroup differences: Q-test $p=0.02$ and $\mathrm{I}^{2}=$ $69.7 \%$, which showed that the data of subgroups were consistent.

The data of subgroup using $0.1 \%$ EGCG as primer showed no statistically significant differences compared with control group (Z-test: $p>0.05$ ). However, the result of proanthocyanidin (PA) showed that the experimental groups had significant higher bond strengths than the control groups, with overall effect $p<0.05$. For primers with $5 \% \mathrm{PA}$ and $6.5 \% \mathrm{PA}$, the result in the Q-test was both $p<0.01$ and $\mathrm{I}^{2}=98 \%, \mathrm{I}^{2}=91 \%$, separately. However, the result of $10 \% \mathrm{PA}$ in the Q-test was $p>0.05$ and $\mathrm{I}^{2}=0 \%$. The results of the meta-analysis are shown in Figure 3.

\section{Self-Etch Bond Strength (Plant Extract Primers)}

For the second analysis (self-etch adhesive with or without plant extract primers), 10 data sets were selected, with four studies 


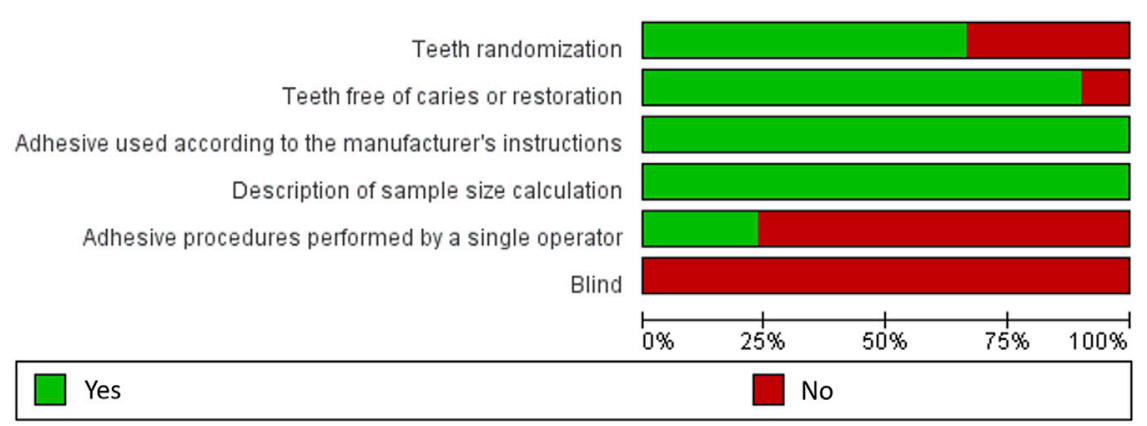

FIGURE 2 | Risk of bias graph judgements about each risk of bias item presented as percentages across all included studies.

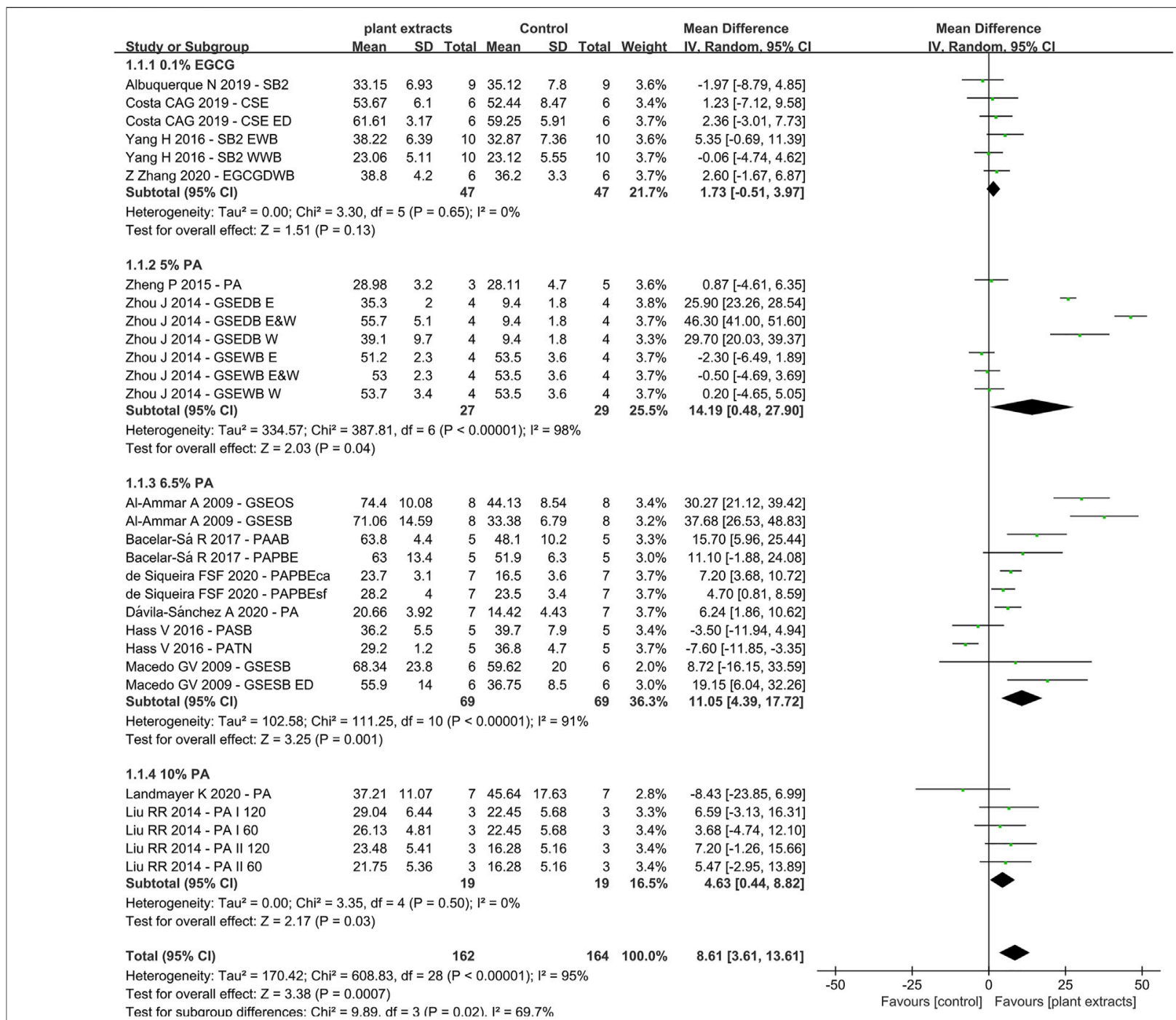

FIGURE 3 | Forest Plot-plant extract primers: etch-and-rinse immediate bond strength. 


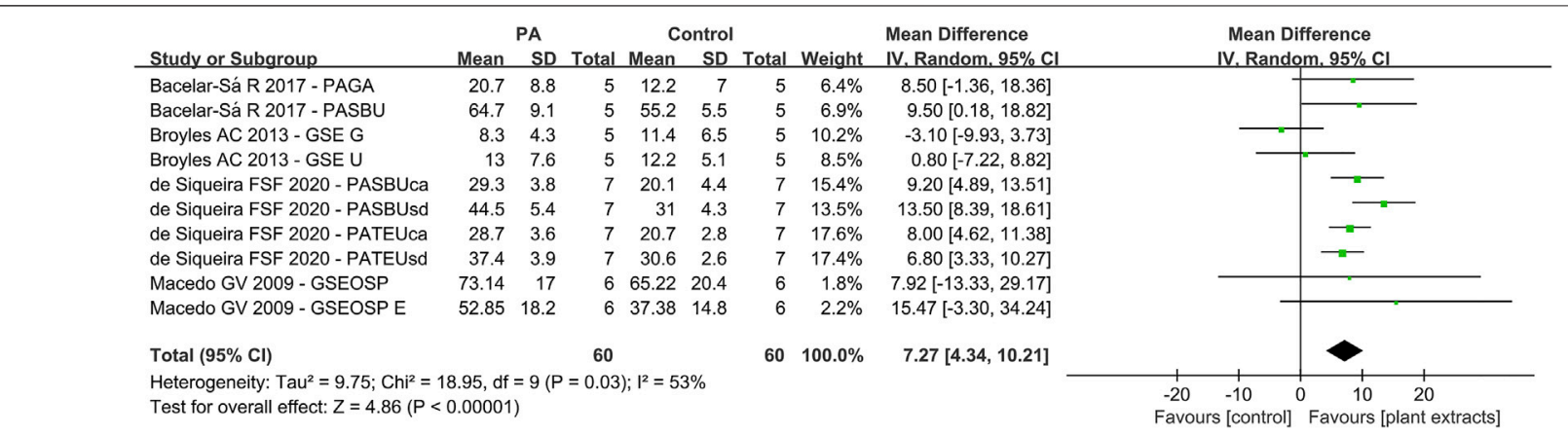

FIGURE 4 | Forest Plot-plant extract primers: self-etch immediate bond strength.

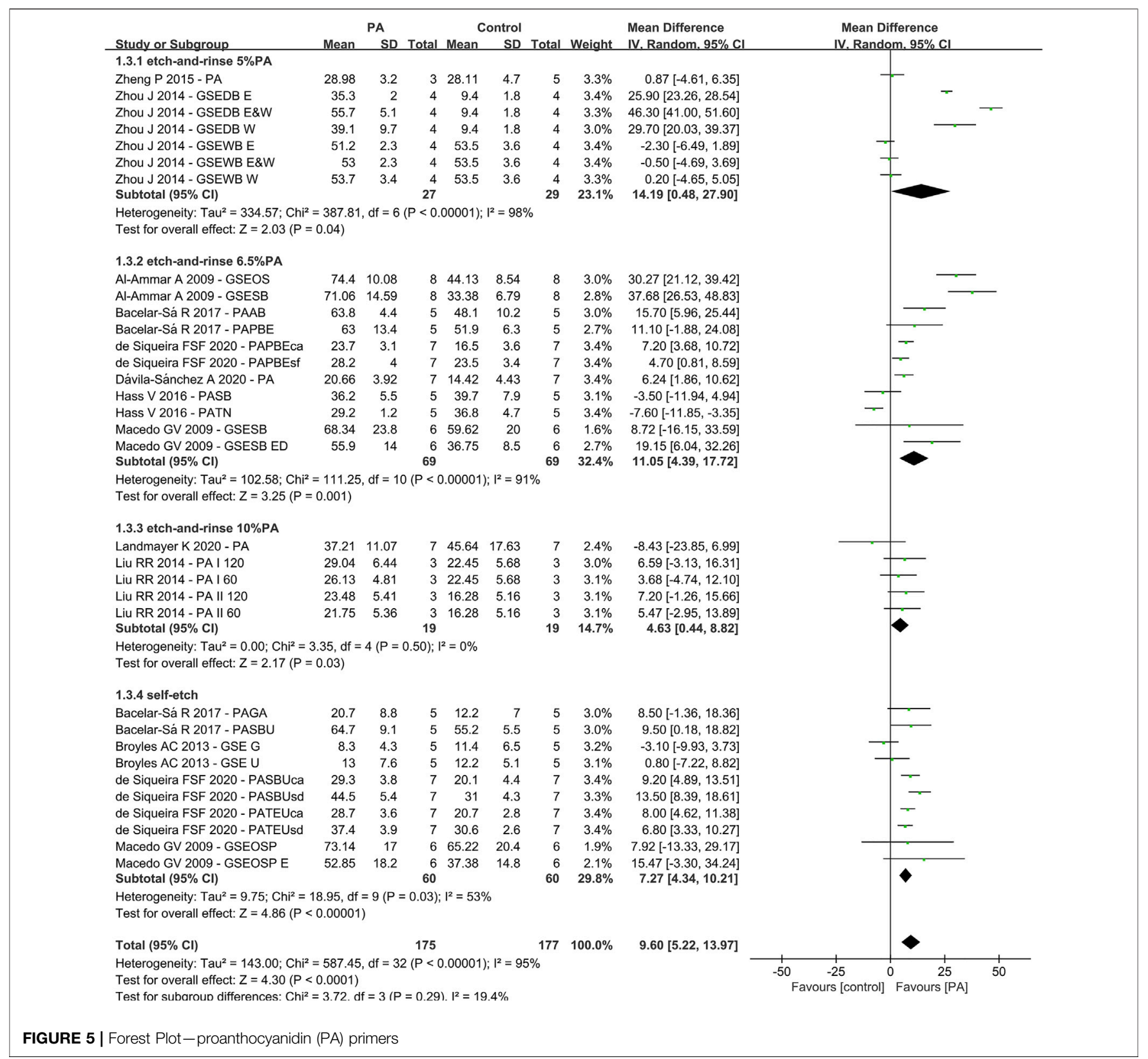


included (Figure 4). The results were as followings: Q-test $p<$ 0.05 and $\mathrm{I}^{2}=53 \%$. The global analysis showed statistically significant difference $(p<0.05)$.

\section{Primers With Vs Without Proanthocyanidin}

For the third analysis (primers with or without PA), 11 studies and 33 datasets were included (Figure 5). The difference between control and experimental groups were statistically significant (Q-test: $p<0.01, \mathrm{I}^{2}=95 \%$ and Z-test: $p<0.05$ ). The differences in the test for subgroups (primers with different concentration of PA) showed the following values: chi-squared $=3.72, \mathrm{df}=3(p=0.29)$ and $\mathrm{I}^{2}=19.4 \%$. The meta-analysis results are shown in Figure 5.

\section{DISCUSSION}

This systematic review is the first to verify the effects of plant extracts on dentin bonding strength from in vitro studies. Thorough database research was conducted, and data were extracted and integrated in tables. Each study was designed and performed on the basis of their own parameters (plant extract types, action modes, concentration, dental adhesives and indicators), as listed in Table 1. Nine different plant extracts were added into 15 types of adhesives or served as primers. Out of the 30 studies, the data from 14 were selected for further evaluation.

As shown in Table 1, there were different commercial adhesives used. We had undertaken several measures to avoid the discrepancy. Firstly, the details of the adhesives were listed, such as commercial name, manufacturer, and place of production. Secondly, the articles that used experimental adhesives were excluded in the present study. Thirdly, 19 of 30 included studies chose the same one commercial adhesive, Single Bond 2(3M ESPE, St. Paul, MN, United States). Furthermore, all included studies set the control group which did not add plant extracts into adhesives or serve as primers. All these strategies were helpful to eliminate the disturbance of different adhesives on research results to the utmost extent. Furthermore, the included studies all reported the manufacturers and details of plant extracts, such as resveratrol powder (Sigma-Aldrich, St. Louis, MO, United States), and the pureness of this product was listed as $\geq 99 \%$ (HPLC).

Since plant extract was introduced, its effectiveness in crosslinking and biocompatibility has drawn a lot of attention. Different plant extracts were investigated, listing as follows: proanthocyanidin (PA), epigallocatechin-3-gallate (EGCG), quercetin (QUE), resveratrol (RSV), baicalein (BAI), hesperidin (HES), rutin (RUT) and naringin (NAR). Firstly, despite the chemical structure differences, they all belong to plant polyphenol, which possesses antioxidant and anti-inflammatory properties. These effects are mainly derived from phenolic hydroxyl groups in polyphenols (Leopoldini et al., 2011). The highly-hydroxylated structures make them capable of forming insoluble complexes with carbohydrates and proteins (Bravo, 1998; Teixeira et al., 2002). The major force that stabilizes the plant-extract-protein complexes is hydrogen bonding between phenolic hydroxyl and peptide carbonyl (Hagerman and Butler, 1980a; Hagerman and Butler, 1980b), which is strengthened by alkyl substitution on the amide nitrogen adjacent to the carbonyl (Cannon, 1955). Therefore, the mechanical properties of collagen complex would be increased (Yang et al., 2016). Secondly, plant extracts, such as baicalein and resveratrol, can inhibit the activity of peptidases directly or indirectly by changing the catalytic domain (Mazzoni et al., 2018) or crosslinking with noncollagenous proteins regulating peptidases (Breschi et al., 2010; Cova et al., 2011). Thirdly, many plant extracts, like baicalein, are commonly used in herbal medicines to treat bacterial and viral infections. They show remarkable antimicrobial effects on different bacteria including Escherichia coli, P. cuspidatum and S.mutans (Song et al., 2006; Duan et al., 2007; Zeng et al., 2008; Chinnam et al., 2010; Jang et al., 2014). The mechanisms are not clear yet, but it might be attributed to the inhibition of the cellular growth (Paulo et al., 2010).

One of the most studied plant extracts is proanthocyanidin (PA), also known as grape seed extracts (GSE) (Al-Ammar et al., 2009; Macedo et al., 2009; Liu et al., 2012; Broyles et al., 2013; Liu et al., 2014; Islam et al., 2014; Zheng et al., 2015; Zhou et al., 2016; Hass et al., 2016b; Bacelar-Sa et al., 2017; Zheng and Chen, 2017; de Siqueira et al., 2020; Ds et al., 2020; Landmayer et al., 2020). It is a condensed tannins extracted from Vitis vinifera grapes, which has been reported to contain $79.6 \%$ polyphenols(Aguiar et al., 2014). PA is composed of flavon-3-ol subunits, catechin, epicatechin and epicatechin-3-O-gallate and linked through C4-C8 (Cavaliere et al., 2010). These components are responsible for their properties such as free-radical scavenging capacity, high affinity for protein, antioxidant potential and capacity to enhance the mechanical properties of collagen (Castellan et al., 2010; Leme-Kraus et al., 2017). Epasinghe et al. (2012) reported that incorporation of less than $3 \%$ proanthocyanidin into dental adhesive can reduce nanoleakage without comprising $24 \mathrm{~h}$ adhesive-dentin bond strength. The meta-analysis of the PA primer effects on bonding showed a significant positive effect compared with the control group, irrespective of the concentrations or the type of adhesive used (Al-Ammar et al., 2010; Macedo et al., 2009; Liu et al., 2014; Wiegand et al., 2015; Zhou et al., 2016; Hass et al., 2016a; BacelarSa et al., 2017; Ds et al., 2020; Landmayer et al., 2020; Siqueira et al., 2020). However, the results of 5 and $6.5 \%$ PA primer revealed a heterogeneity of $98 \%$ and $91 \%$ (Figure 3). The reason might be attributed to different bonding techniques such as dry bonding and wet bonding (Zhou et al., 2016) For 10\% PA primer, the bonding strength shows statistically significant elevation with no heterogeneity (Liu et al., 2014; Landmayer et al., 2020). Although the heterogeneity varies from group to group, the subgroup analysis revealed no significant differences, which also prove the effectiveness of PA primer.

Another important plant extract being intensely investigated is epigallocatechin-3-gallate (EGCG) (Du et al., 2012; Santiago et al., 2013; Yang et al., 2016; Yu et al., 2017; Albuquerque et al., 2019; Costa et al., 2019; Fialho et al., 2019; Landmayer et al., 2020; Zhang et al., 2020). It is one of the flavanols in tea, also known as catechins (Tachibana, 2011). As a representative component of green tea, it cannot be found in any plants except C. sinensis (L.) Kuntze (Tachibana, 2011). EGCG consists of a meta-5,7dihydroxyl-substituted A ring and trihydroxy phenol structures 
TABLE 3 | Physical and chemical properties of the plant extracts and their possible effects on immediate bonding strength.

\begin{tabular}{|c|c|c|c|c|}
\hline Plant extracts & Molecular formula & Mol. Weight (g/mol) & $\begin{array}{l}\text { Number of hydroxyphenyl } \\
\text { radicals }\end{array}$ & $\begin{array}{l}\text { Effects on immediate } \\
\text { bonding strength }\end{array}$ \\
\hline Proanthocyanidin & $\mathrm{C}_{30} \mathrm{H}_{26} \mathrm{O}_{13}$ & 594.5 & 7 & \\
\hline Epigallocatechin gallate & $\mathrm{C}_{22} \mathrm{H}_{18} \mathrm{O}_{11}$ & 458.4 & 8 & \\
\hline Resveratol & $\mathrm{C}_{14} \mathrm{H}_{12} \mathrm{O}_{3}$ & 228.2 & 3 & \\
\hline Baicalein & $\mathrm{C}_{15} \mathrm{H}_{10} \mathrm{O}_{5}$ & 270.2 & 3 & \\
\hline Rutin & $\mathrm{C}_{27} \mathrm{H}_{30} \mathrm{O}_{16}$ & 610.5 & 4 & \\
\hline Naringin & $\mathrm{C}_{27} \mathrm{H}_{32} \mathrm{O}_{14}$ & 580.5 & 2 & \\
\hline
\end{tabular}

on both the B and D rings (Peter et al., 2017). The polyphenolic structure makes EGCG good donors for hydrogen bonding (Yang et al., 2009). Thus, it has shown the ability to bring various health benefits, like anti-metastasis, anti-inflammatory and antioxidant effects (Mukhtar and Ahmad, 2000; Mereles and Hunstein, 2011; Suzuki and Isemura, 2013). The similarity of chemical structure with other flavanols like PA makes it capable of enhancing the mechanical strength of collagen. The addition of EGCG directly into adhesives has been proven to preserve the bond strength after different ageing methods (Du et al., 2012; Yu et al., 2017; Albuquerque et al., 2019). The result of EGCG primer showed no negative influence on immediate bond strength (Zhang et al., 2020). The lack of data and various ageing methods make it impossible to do meta-analysis on aged bond strength. However, plenty of articles showed EGCG primer can improve the bond stability (Landmayer et al., 2020; Zhang et al., 2020). Furthermore, Yu et al. (2017) created a derivative of EGCG, called EGCG-3Me, which can enhance the bond stability, inhibited S.mutans adhesion and hinder its growth.

There are other plant extracts included in this systematic review: quercetin (QUE) (Gotti et al., 2015; Yang et al., 2017; Ds et al., 2020), resveratrol (RSV) (Porto et al., 2018; Peng et al., 2020), baicalein (BAI) (J. Li et al., 2018; Yi et al., 2019), genipin (GEN) (Al-Ammar et al., 2009), hesperidin (HES) (Islam et al., 2014; Ds et al., 2020), rutin (RUT) (Ds et al., 2020), and naringin (NAR) (Ds et al., 2020). The molecular formula, mass and number of hydroxyphenyl radicals are listed in Table 3. The data are inadequate to perform meta-analysis.

As natural crosslinkers, there are many factors influencing the crosslinking process. For instance, 1) the molecule size; 2) the number of molecules available in the solution; 3 ) the solubility index of the molecule and its influence on the miscibility of the vehicle for its application in dentin; 4) the number and type of reactive sites of the molecule; 5) the characteristics of the dentin (Ds et al., 2020).

It is a paradox that the bigger molecules usually have more reactive sites that can enhance the crosslinking effect, but their ability to dissolve and diffuse would be lower than smaller ones. Moreover, the type of molecules in grape seed extracts are complex, with monomers, oligomers and polymers existing at the same time (Bravo, 1998). The size of the oligomers and polymers were larger, which makes it more difficult to diffuse into dentin tubules. According to the results of included studies, we concluded the possible effects of different plant extracts on immediate bonding strength and classified them into different colors: green means the effects on improving bonding strength were evident; yellow means more studies in need; red means probable adverse effects (Table 3 ).

The plant extracts are normally recognized as plant polyphenols, which encompass a wide variety of molecules that contain at least one aromatic ring with one or more hydroxyl groups (Ferrazzano et al., 2011). Although they were extracted from different plants, the similarity in their chemical structure makes it possible for them to all possess properties like antioxidation and anti-bacterium. To begin with, the highlyhydroxylated structures make them capable of forming complexes with proteins, especially proline-rich proteins in dental collagen (Bravo, 1998). This fortified crosslinking interaction helps enhance the mechanical strength of dental bonding (Yang et al., 2017; Yi et al., 2019; Peng et al., 2020). Furthermore, the polyphenolic compounds could coordinate with metal ions and compete with peptidases such as MMPs for the catalytic domain in collagen (Mazzoni et al., 2018). As a 
result, the enzymatic hydrolysis of hybrid layer collagen would be impeded and the adhesive-dentin interface stability would be maintained (Epasinghe et al., 2012; Yang et al., 2016; Yang et al., 2017). Besides, the plant polyphenols were considered metabolites involved in the chemical defense of plants and possess the ability to inhibit bacteria (Ferrazzano et al., 2011). There is plenty of evidence supporting the inhibition of cariogenic bacteria by phenolic compounds. The mechanisms of polyphenols against bacteria like S.mutans may include affecting cell membrane permeability, inhibiting protein synthesis, blocking ATP synthesis and inhibiting bacterial metabolism (Chinnam et al., 2010; Xie et al., 2015). Lastly, as natural crosslinkers, the plant polyphenols are non-toxic compared to synthetic compounds like chlorhexidine and glutaraldehyde. They can protect cells by inhibiting oxidative stress-induced DNA damage, lipid peroxidation and protein oxidation (Kang et al., 2012). To conclude, all these in vitro studies demonstrated that the plant extracts, consisting of polyphenols, can enhance mechanical strength of dentin collagen, maintain dentin-adhesive stability, inhibit cariogenic bacteria and resist adhesive-induced cytotoxicity.

Although plant extracts have shown plenty of advantages, there are still a large variety of aspects to be explored, such as solvent, treatment time and concentrations. First, theoretically, the effect of plant extracts would increase with the concentration. However, the solubility of the compounds were not great (Bravo, 1998). Zhang et al. (2020) reported EGCG with dimethyl sulfoxide as a solvent can exert synergistic effect on dentinadhesive interface stability. Second, the treatment time varies from one to another. Genipin is reported to have a slow rate of cross-linking induction that the mechanical strength increased only after $40 \mathrm{~h}$ treatment (Bedran-Russo et al., 2007). Third, the effect of different concentration on bonding is complex. It has been shown more than 3\% PA added into adhesive directly can exert adverse effect on bonding (Epasinghe et al., 2012). More studies are needed to determine the suitable solvent, treatment time and concentrations of plant extracts.

As mentioned in this review, plant extracts are actually polyphenols, which possess phenolic hydroxyl groups and aromatic rings (Ferrazzano et al., 2011). Therefore, their solubility in solvents such as ethanol are high, due to their similar chemical structure like hydroxyl groups. Furthermore, the interactions between plant extract (eg. PA) and collagen can be disrupted by detergents of hydrogen bond-weakening solvents, suggesting that PA-collagen complex formation involves primarily hydrogen bonding between the protein amide carbonyl and the phenolic hydroxyl (Hagerman and Klucher, 1986). Ethanol, on the other hand, stimulate PA and collagen interactions (Bo et al., 2010). There is no evidence that the interaction is concentration-dependent.

\section{REFERENCES}

Aguiar, T. R., Vidal, C. M. P., Phansalkar, R. S., Todorova, I., Napolitano, J. G., Mcalpine, J. B., et al. (2014). Dentin Biomodification Potential Depends on
The present study showed the changes in dentin bond strength after adding plant extracts into adhesives or serving as primers. Although strict selection was performed to minimize heterogeneity, the data of several subgroups remained high heterogeneous. There are three reasons for heterogeneity:1. Different adhesive brands; 2. Different bonding modes (etchand-rinse or self-etch); 3. Different dentin material (normal or eroded dentin). Also, several authors failed to report important details, such as whether the same operator performed the bonding steps of all specimens. These factors may help explain the high heterogeneity in in vitro experiments.

\section{CONCLUSIONS}

Plant extracts have positive effects on the immediate microtensile bond strength of the adhesive-dentin interface. Meta-analysis demonstrated that the use of proanthocyanidin (PA) primer, especially at the concentration of $10 \%$, had statistically significant effect on the immediate dentin bonding strength. Considerable heterogeneity existed among the different adhesive brands, bonding modes and dentin materials used, which limited the meta-analysis approach. Further clinical research is needed to confirm the effect of plant extracts on bond strength in vivo.

\section{DATA AVAILABILITY STATEMENT}

The original contributions presented in the study are included in the article/Supplementary Material, further inquiries can be directed to the corresponding authors.

\section{AUTHOR CONTRIBUTIONS}

The conception and design of the study were performed by HY and $\mathrm{CH}$. Literature retrieving and studies selection were performed by SZ and JY. Quality evaluation was carried out by $\mathrm{CH}$ and JY. Mathematical modeling and meta-analysis were conducted by FH and SZ. Results analysis and interpretation were undertaken by HY and SZ. The manuscript was drafted by HY and SZ. All authors read and approved the final manuscript.

\section{FUNDING}

This work was financially supported by National Natural Science Foundation of China (81701012), Youth Clinical Research Fund of Chinese Stomatological Association (CSAB2018-01).

Polyphenol Source. J. Dent Res. 93 (4), 417-422. doi:10.1177/ 0022034514523783

Al-Ammar, A., Drummond, J. L., and Bedran-Russo, A. K. (2010). The Use of Collagen Cross-Linking Agents to Enhance Dentin Bond Strength. J. Biomed. Mater. Res. B Appl. Biomater. 91 (1), 419-424. doi:10.1002/jbm.b.31417 
Al-Ammar, A., Drummond, J. L., and Bedran-Russo, A. K. (2009). The Use of Collagen Cross-Linking Agents to Enhance Dentin Bond Strength. J. Biomed. Mater. Res. 91B (1), 419-424. doi:10.1002/jbm.b.31417

Albuquerque, N., Neri, J. R., Lemos, M., Yamauti, M., de Sousa, F., and Santiago, S. (2019). Effect of Polymeric Microparticles Loaded with Catechin on the Physicochemical Properties of an Adhesive System. Oper. Dent 44 (4), E202-E211. doi:10.2341/18-112-L

Alkatheeri, M. S., Palasuk, J., Eckert, G. J., Platt, J. A., and Bottino, M. C. (2015). Halloysite Nanotube Incorporation into Adhesive Systems-Effect on Bond Strength to Human Dentin. Clin. Oral Invest. 19 (8), 1905-1912. doi:10.1007/s00784-015-1413-8

Bacelar-Sá, R., Giannini, M., Ambrosano, G. M. B., and Bedran-Russo, A. K. (2017). Dentin Sealing and Bond Strength Evaluation of Hema-free and MultiMode Adhesives to Biomodified Dentin. Braz. Dent. J. 28 (6), 731-737. doi:10. 1590/0103-6440201701522

Bedran-Russo, A. K. B., Pereira, P. N. R., Duarte, W. R., Drummond, J. L., and Yamauchi, M. (2007). Application of Crosslinkers to Dentin Collagen Enhances the Ultimate Tensile Strength. J. Biomed. Mater. Res. 80B (1), 268-272. doi:10. 1002/jbm.b.30593

Bo, H., Jaurequi, J., Bao, W. T., and Nimni, M. E. (2010). Proanthocyanidin: a Natural Crosslinking Reagent for Stabilizing Collagen Matrices. J. Biomed. Mater. Res. A 65A.

Borges, B. C. D., Catelan, A., Sasaki, R. T., Ambrosano, G. M. B., Reis, A. F., and Aguiar, F. H. B. (2013). Effect of the Application of a Casein PhosphopeptideAmorphous Calcium Phosphate (CPP-ACP) Paste and Adhesive Systems on Bond Durability of a Fissure Sealant. Odontology 101 (1), 52-59. doi:10.1007/ s10266-012-0062-5

Brackett, M. G., Li, N., Brackett, W. W., Sword, R. J., Qi, Y. P., Niu, L. N., et al. (2011). The Critical Barrier to Progress in Dentine Bonding with the Etch-AndRinse Technique. J. Dentistry 39 (3), 238-248. doi:10.1016/j.jdent.2010.12.009

Bravo, L. (1998). Polyphenols: Chemistry, Dietary Sources, Metabolism, and Nutritional Significance. Nutr. Rev. 56 (11), 317-333. doi:10.1111/j.17534887.1998.tb01670.x

Breschi, L., Mazzoni, A., Nato, F., Carrilho, M., Visintini, E., Tjäderhane, L., et al. (2010). Chlorhexidine Stabilizes the Adhesive Interface: a 2-year In Vitro Study. Dental Mater. 26 (4), 320-325. doi:10.1016/j.dental.2009.11.153

Broyles, A. C., Pavan, S., and Bedran-Russo, A. K. (2013). Effect of Dentin Surface Modification on the Microtensile Bond Strength of Self-Adhesive Resin Cements. J. Prosthodont. 22 (1), 59-62. doi:10.1111/j.1532-849X.2012.00890.x

Cannon, C. G. (1955). The Interactions and Structure of the -CONH- Group in Amides and Polyamides. Microchimica Acta 43 (2-3), 555-588. doi:10.1007/bf01235027

Carrilho, M. R. O., Carvalho, R. M., de Goes, M. F., di Hipólito, V., Geraldeli, S., Tay, F. R., et al. (2007). Chlorhexidine Preserves Dentin Bond In Vitro. J. Dent Res. 86 (1), 90-94. doi:10.1177/154405910708600115

Castellan, C. S., Pereira, P. N., Grande, R. H. M., and Bedran-Russo, A. K. (2010). Mechanical Characterization of Proanthocyanidin-Dentin Matrix Interaction. Dental Mater. 26 (10), 968-973. doi:10.1016/j.dental.2010.06.001

Cavaliere, C., Foglia, P., Gubbiotti, R., Sacchetti, P., Samperi, R., and Laganà, A. (2010). Rapid-resolution Liquid Chromatography/mass Spectrometry for Determination and Quantitation of Polyphenols in Grape Berries. Rapid Commun. Mass. Spectrom. 22 (20), 3089-3099. doi:10.1002/rcm.3705

Chinnam, N., Dadi, P. K., Sabri, S. A., Ahmad, M., Kabir, M. A., and Ahmad, Z. (2010). Dietary Bioflavonoids Inhibit Escherichia coli ATP Synthase in a Differential Manner. Int. J. Biol. Macromolecules 46 (5), 478-486. doi:10. 1016/j.ijbiomac.2010.03.009

Costa, C. A. G., Passos, V. F., Neri, J. R., Mendonça, J. S., and Santiago, S. L. (2019). Effect of Metalloproteinase Inhibitors on Bond Strength of a Self-Etching Adhesive on Erosively Demineralized Dentin. J. Adhes. Dent 21 (4), 337-344. doi:10.3290/j.jad.a42930

Cova, A., Breschi, L., Nato, F., Ruggeri, A., Jr., Carrilho, M., Tjäderhane, L., et al. (2011). Effect of UVA-Activated Riboflavin on Dentin Bonding. J. Dent Res. 90 (12), 1439-1445. doi:10.1177/0022034511423397

de Siqueira, F. S. F., Hilgemberg, B., Araujo, L. C. R., Hass, V., Bandeca, M. C., Gomes, J. C., et al. (2020). Improving Bonding to Eroded Dentin by Using Collagen Cross-Linking Agents: 2 Years of Water Storage. Clin. Oral Invest. 24 (2), 809-822. doi:10.1007/s00784-019-02918-9

Deligeorgi, V., Mjör, I. A., and Wilson, N. H. (2001). An Overview of Reasons for the Placement and Replacement of Restorations. Prim. Dental Care os8 (1), 5-11. doi:10.1308/135576101771799335
Deng, D., Yang, H., Guo, J., Chen, X., Zhang, W., and Huang, C. (2014). Effects of Different Artificial Ageing Methods on the Degradation of Adhesive-Dentine Interfaces. J. Dentistry 42 (12), 1577-1585. doi:10.1016/j.jdent.2014.09.010

Drummond, J. L. (2008). Degradation, Fatigue, and Failure of Resin Dental Composite Materials. J. Dent Res. 87 (8), 710-719. doi:10.1177/ 154405910808700802

Ds, A., Mfgb, C., Jpb, D., Mbd, E., Bh, D., Ss, F., et al. (2020). Influence of Flavonoids on Long-Term Bonding Stability on Caries-Affected Dentin - ScienceDirect. Dental Mater. 36 (9), 1151-1160. doi:10.1016/j.dental.2020.05.007

Du, X., Huang, X., Huang, C., Wang, Y., and Zhang, Y. (2012). Epigallocatechin-3gallate (EGCG) Enhances the Therapeutic Activity of a Dental Adhesive. J. Dentistry 40 (6), 485-492. doi:10.1016/j.jdent.2012.02.013

Duan, C., Matsumura, S., Kariya, N., Nishimura, M., and Shimono, T. (2007). In Vitro antibacterial Activities of Scutellaria Baicalensis Georgi against Cariogenic Bacterial. Pediatr. Dental J. 17 (1), 58-64. doi:10.1016/s0917-2394(07)70096-4

Epasinghe, D. J., Yiu, C. K. Y., Burrow, M. F., Tay, F. R., and King, N. M. (2012). Effect of Proanthocyanidin Incorporation into Dental Adhesive Resin on Resin-Dentine Bond Strength. J. Dentistry 40 (3), 173-180. doi:10.1016/j.jdent.2011.11.013

Ferrazzano, G., Amato, I., Ingenito, A., Zarrelli, A., Pinto, G., and Pollio, A. (2011). Plant Polyphenols and Their Anti-cariogenic Properties: a Review. Molecules 16 (2), 1486-1507. doi:10.3390/molecules16021486

Fialho, M. P. N., Hass, V., Nogueira, R. P., França, F. M. G., Turssi, C. P., Basting, R. T., et al. (2019). Effect of Epigallocatechin-3- Gallate Solutions on Bond Durability at the Adhesive Interface in Caries-Affected Dentin. J. Mech. Behav. Biomed. Mater. 91, 398-405. doi:10.1016/j.jmbbm.2018.11.022

Gotti, V. B., Feitosa, V. P., Sauro, S., Correr-Sobrinho, L., Leal, F. B., Stansbury, J. W., et al. (2015). Effect of Antioxidants on the Dentin Interface Bond Stability of Adhesives Exposed to Hydrolytic Degradation. J. Adhes. Dent 17 (1), 35-44. doi:10.3290/j.jad.a33515

Hagerman, A. E., and Klucher, K. M. (1986). Tannin-protein Interactions. Prog. Clin. Biol. Res. 213 (3), 67-76.

Hagerman, A. E., and Butler, L. G. (1980a). Condensed Tannin Purification and Characterization of Tannin-Associated Proteins. J. Agric. Food Chem. 28 (5), 947-952. doi:10.1021/jf60231a011

Hagerman, A. E., and Butler, L. G. (1980b). Determination of Protein in Tannin-Protein Precipitates. J. Agric. Food Chem. 28 (5), 944-947. doi:10.1021/jf60231a010

Hass, V., Luque-Martinez, I., Muñoz, M. A., Reyes, M. F., Abuna, G., Sinhoreti, M. A., et al. (2016a). The Effect of Proanthocyanidin-Containing 10\% Phosphoric Acid on Bonding Properties and MMP Inhibition. Dent Mater. 32 (3), 468-475. doi:10.1016/j.dental.2015.12.007

Hass, V., Luque-Martinez, I. V., Gutierrez, M. F., Moreira, C. G., Gotti, V. B., Feitosa, V. P., et al. (2016b). Collagen Cross-Linkers on Dentin Bonding: Stability of the Adhesive Interfaces, Degree of Conversion of the Adhesive, Cytotoxicity and In Situ MMP Inhibition. Dental Mater. 32 (6), 732-741. doi:10.1016/j.dental.2016.03.008

Islam, M. S., Hiraishi, N., Nassar, M., Yiu, C., Otsuki, M., and Tagami, J. (2014). Effect of Hesperidin Incorporation into a Self-Etching Primer on Durability of Dentin Bond. Dental Mater. 30 (11), 1205-1212. doi:10.1016/j.dental.2014.08.371

Jang, E.-J., Cha, S.-M., Choi, S.-M., and Cha, J.-D. (2014). Combination Effects of Baicalein with Antibiotics against Oral Pathogens. Arch. Oral Biol. 59 (11), 1233-1241. doi:10.1016/j.archoralbio.2014.07.008

Kang, K. A., Zhang, R., Piao, M. J., Chae, S., Kim, H. S., Park, J. H., et al. (2012). Baicalein Inhibits Oxidative Stress-Induced Cellular Damage via Antioxidant Effects. Toxicol. Ind. Health 28 (5), 412-421. doi:10.1177/0748233711413799

Kaul, T. N., Middleton, E., Jr., and Ogra, P. L. (1985). Antiviral Effect of Flavonoids on Human Viruses. J. Med. Virol. 15 (1), 71-79. doi:10.1002/jmv.1890150110

La, V. D., Howell, A. B., and Grenier, D. (2009). Cranberry Proanthocyanidins Inhibit MMP Production and Activity. J. Dent Res. 88 (7), 627-632. doi:10. $1177 / 0022034509339487$

Landmayer, K., Liberatti, G. A., Farias-Neto, A. M., Wang, L., Honório, H. M., and Francisconi-Dos-Rios, L. F. (2020). Could Applying Gels Containing Chlorhexidine, Epigallocatechin-3-Gallate, or Proanthocyanidin to Control Tooth Wear Progression Improve Bond Strength to Eroded Dentin. J. Prosthet Dent 124 (6), 798-e7. doi:10.1016/j.prosdent.2020.05.032

Leme-Kraus, A. A., Aydin, B., Vidal, C. M., Phansalkar, R. M., Nam, J. W., Mcalpine, J., et al. (2017). Biostability of the Proanthocyanidins-Dentin Complex and Adhesion Studies. J. Dent Res. 96 (4), 412-406. doi:10.1177/ 0022034516680586 
Leopoldini, M., Russo, N., and Toscano, M. (2011). The Molecular Basis of Working Mechanism of Natural Polyphenolic Antioxidants. Food Chem. 125 (2), 288-306. doi:10.1016/j.foodchem.2010.08.012

Li, J., Chen, B., Hong, N., Wu, S., and Li, Y. (2018). Effect of Baicalein on Matrix Metalloproteinases and Durability of Resin-Dentin Bonding. Oper. Dent 43 (4), 426-436. doi:10.2341/17-097-L

Li, K., Yang, H., Yan, H., Sun, Y., Chen, X., Guo, J., et al. (2017). Quercetin as a Simple but Versatile Primer in Dentin Bonding. Rsc Adv. 7, 36392-36402. doi:10.1039/c7ra07467k

Liu, R.-R., Fang, M., Zhang, L., Tang, C.-F., Dou, Q., and Chen, J.-H. (2014). Antiproteolytic Capacity and Bonding Durability of Proanthocyanidin-Biomodified Demineralized Dentin Matrix. Int. J. Oral Sci. 6 (3), 168-174. doi:10.1038/ijos.2014.22

Liu, R. R., Fang, M., Zhao, S. J., Li, F., Shen, L. J., and Chen, J. H. (2012). The Potential Effect of Proanthocyanidins on the Stability of Resin-Dentin Bonds against thermal Cycling. Zhonghua Kou Qiang Yi Xue Za Zhi 47 (5), 268-272. doi:10.3760/cma.j.issn.1002-0098.2012.05.004

Macedo, G. V., Yamauchi, M., and Bedran-Russo, A. K. (2009). Effects of Chemical Cross-Linkers on Caries-Affected Dentin Bonding. J. Dent Res. 88 (12), 1096-1100. doi:10.1177/0022034509351001

Mazzoni, A., Angeloni, V., Comba, A., Maravic, T., Cadenaro, M., Tezvergil-Mutluay, A., et al. (2018). Cross-linking Effect on Dentin Bond Strength and MMPs Activity. Dental Mater. 34 (2), 288-295. doi:10.1016/j.dental.2017.11.009

Mereles, D., and Hunstein, W. (2011). Epigallocatechin-3-gallate (EGCG) for Clinical Trials: More Pitfalls Than Promises. Ijms 12 (9), 5592-5603. doi:10. 3390/ijms12095592

Mjör, I. A., Moorhead, J. E., and Dahl, J. E. (2000). Reasons for Replacement of Restorations in Permanent Teeth in General Dental Practice. Int. Dental J. 50 (6), 361-366. doi:10.1111/j.1875-595x.2000.tb00569.x

Mukhtar, H., and Ahmad, N. (2000). Tea Polyphenols: Prevention of Cancer and Optimizing Health. Am. J. Clin. Nutr. 71 (6 Suppl. 1), 1698S-1702S. doi:10.1093/ ajcn/71.6.1698S

Paulo, S., L., Ferreira, S., and Gallardo, E. F. (2010). Antimicrobial Activity and Effects of Resveratrol on Human Pathogenic Bacteria. WORLD JOURNAL MICROBIOLOGY BIOTECHNOLOGY 53 (6), 716-723. doi:10.1007/s11274-010-0325-7

Peng, W., Yi, L., Wang, Z., Yang, H., and Huang, C. (2020). Effects of Resveratrol/ ethanol Pretreatment on Dentin Bonding Durability. Mater. Sci. Eng. C 114, 111000. doi:10.1016/j.msec.2020.111000

Peter, B., Bosze, S., and Horvath, R. (2017). Biophysical Characteristics of Proteins and Living Cells Exposed to the green tea Polyphenol Epigallocatechin-3-Gallate (EGCg): Review of Recent Advances from Molecular Mechanisms to Nanomedicine and Clinical Trials. Eur. Biophys. J. 46 (1), 1-24. doi:10.1007/s00249-016-1141-2

Porto, I. C. C. M., Nascimento, T. G., Oliveira, J. M. S., Freitas, P. H., Haimeur, A., and França, R. (2018). Use of Polyphenols as a Strategy to Prevent Bond Degradation in the Dentin-Resin Interface. Eur. J. Oral Sci. 126 (2), 146-158. doi:10.1111/eos.12403

Rigano, D., Formisano, C., Basile, A., Lavitola, A., Senatore, F., Rosselli, S., et al. (2007). Antibacterial Activity of Flavonoids and Phenylpropanoids fromMarrubium Globosumssp. Libanoticum. Phytother. Res. 21 (4), 395-397. doi:10.1002/ptr.2061

Santiago, S. L., Osorio, R., Neri, J. R., Carvalho, R. M., and Toledano, M. (2013). Effect of the Flavonoid Epigallocatechin-3-Gallate on Resin-Dentin Bond Strength. J. Adhes. Dent 15 (6), 535-540. doi:10.3290/j.jad.a29532

Sarkis-Onofre, R., Skupien, J., Cenci, M., Moraes, R., and Pereira-Cenci, T. (2014). The Role of Resin Cement on Bond Strength of Glass-Fiber Posts Luted into Root Canals: a Systematic Review and Meta-Analysis of In Vitro Studies. Oper. Dent 39 (1), E31-E44. doi:10.2341/13-070-LIT

Siqueira, F., Hilgemberg, B., Araujo, L., Hass, V., Bandeca, M. C., Gomes, J. C., et al. (2020). Improving Bonding to Eroded Dentin by Using Collagen Cross-Linking Agents: 2years of Water Storage. Clin. Oral Investig. 24 (2), 809-822. doi:10. 1007/s00784-019-02918-9

Song, J.-H., Kim, S.-K., Chang, K.-W., Han, S.-K., Yi, H.-K., and Jeon, J.-G. (2006). In Vitro inhibitory Effects of Polygonum Cuspidatum on Bacterial Viability and Virulence Factors of Streptococcus Mutans and Streptococcus Sobrinus. Arch. Oral Biol. 51 (12), 1131-1140. doi:10.1016/j.archoralbio.2006.06.011

Suzuki, Y., and Isemura, M. (2013). Binding Interaction between (-)-epigallocatechin Gallate Causes Impaired Spreading of Cancer Cells on Fibrinogen. Biomed. Res. 34 (6), 301-308. doi:10.2220/ biomedres.34.301

Tachibana, H. (2011). Green tea Polyphenol Sensing. Proc. Jpn. Acad. Ser. B: Phys. Biol. Sci. 87 (3), 66-80. doi:10.2183/pjab.87.66
Taneja, S., Kumari, M., and Bansal, S. (2017). Effect of Saliva and Blood Contamination on the Shear Bond Strength of Fifth-, Seventh-, and EighthGeneration Bonding Agents: An In Vitro Study. J. Conserv Dent 20 (3), 157-160. doi:10.4103/0972-0707.218310

Teixeira, F., Pollock, M., Karim, A., and Jiang, Y. (2002). Use of Antioxidants for the Prophylaxis of Cold-Induced Peripheral Nerve Injury. Mil. Med. 167 (9), 753-755. doi:10.1093/milmed/167.9.753

Wiegand, A., Zheng, P., and Zaruba, M. T. (2015). Effect of Different Matrix Metalloproteinase Inhibitors on Microtensile Bond Strength of an Etch-And-Rinse and a Self-Etch Adhesive to Dentin. Oper. Dent. 40(1):80-86. doi:10.2341/13-162-L

Xie, Y., Yang, W., Tang, F., Chen, X., and Ren, L. (2014). Antibacterial Activities of Flavonoids: Structure-Activity Relationship and Mechanism. Cmc 22 (1), 132-149. doi:10.2174/0929867321666140916113443

Yang, C. S., Wang, X., Lu, G., and Picinich, S. C. (2009). Cancer Prevention by tea: Animal Studies, Molecular Mechanisms and Human Relevance. Nat. Rev. Cancer 9 (6), 429-439. doi:10.1038/nrc2641

Yang, H., Guo, J., Deng, D., Chen, Z., and Huang, C. (2016). Effect of Adjunctive Application of Epigallocatechin-3-Gallate and Ethanol-Wet Bonding on Adhesive-Dentin Bonds. J. Dentistry 44, 44-49. doi:10.1016/j.jdent.2015.12.001

Yang, H., Li, K., Yan, H., Liu, S., Wang, Y., and Huang, C. (2017). Highperformance Therapeutic Quercetin-Doped Adhesive for Adhesive-Dentin Interfaces. Sci. Rep. 7 (1), 8189. doi:10.1038/s41598-017-08633-3

Yi, L., Yu, J., Han, L., Li, T., Yang, H., and Huang, C. (2019). Combination of Baicalein and Ethanol-Wet-Bonding Improves Dentin Bonding Durability. J. Dentistry 90, 103207. doi:10.1016/j.jdent.2019.103207

Yu, H.-H., Zhang, L., Yu, F., Li, F., Liu, Z.-Y., and Chen, J.-H. (2017) Epigallocatechin-3-gallate and Epigallocatechin-3-O-(3-O-Methyl)-Gallate Enhance the Bonding Stability of an Etch-And-Rinse Adhesive to Dentin. Materials 10 (2), 183. doi:10.3390/ma10020183

Zeng, Z., Qian, L., Cao, L., Tan, H., Huang, Y., Xue, X., et al. (2008). Virtual Screening for Novel Quorum Sensing Inhibitors to Eradicate Biofilm Formation of Pseudomonas aeruginosa. Appl. Microbiol. Biotechnol. 79 (1), 119-126. doi:10.1007/s00253-008-1406-5

Zhang, K., Li, F., Imazato, S., Cheng, L., Liu, H., Arola, D. D., et al. (2013). Dual Antibacterial Agents of Nano-Silver and 12methacryloyloxydodecylpyridinium Bromide in Dental Adhesive to Inhibit Caries. J. Biomed. Mater. Res. 101B (6), 929-938. doi:10.1002/jbm.b.32898

Zhang, Z., Yu, J., Yao, C., Yang, H., and Huang, C. (2020). New Perspective to Improve Dentin-Adhesive Interface Stability by Using Dimethyl Sulfoxide WetBonding and Epigallocatechin-3-Gallate. Dental Mater. 36 (11), 1452-1463. doi:10.1016/j.dental.2020.08.009

Zheng, P., and Chen, H. (2017). Evaluate the Effect of Different Mmps Inhibitors on Adhesive Physical Properties of Dental Adhesives, Bond Strength and Mmp Substarte Activity. Sci. Rep. 7 (1), 4975. doi:10.1038/s41598-017-04340-1

Zheng, P., Zaruba, M., Attin, T., and Wiegand, A. (2015). Effect of Different Matrix Metalloproteinase Inhibitors on Microtensile Bond Strength of an Etch-AndRinse and a Self-Etching Adhesive to Dentin. Oper. Dent 40 (1), 80-86. doi:10. 2341/13-162-L

Zhou, J., Chiba, A., Scheffel, D. L. S., Hebling, J., Agee, K., Tagami, J., et al. (2016). Cross-linked Dry Bonding: A New Etch-And-Rinse Technique. Dental Mater. 32 (9), 1124-1132. doi:10.1016/j.dental.2016.06.014

Conflict of Interest: The authors declare that the research was conducted in the absence of any commercial or financial relationships that could be construed as a potential conflict of interest.

Publisher's Note: All claims expressed in this article are solely those of the authors and do not necessarily represent those of their affiliated organizations, or those of the publisher, the editors and the reviewers. Any product that may be evaluated in this article, or claim that may be made by its manufacturer, is not guaranteed or endorsed by the publisher.

Copyright $\odot 2022$ Zhao, Hua, Yan, Yang and Huang. This is an open-access article distributed under the terms of the Creative Commons Attribution License (CC BY). The use, distribution or reproduction in other forums is permitted, provided the original author(s) and the copyright owner(s) are credited and that the original publication in this journal is cited, in accordance with accepted academic practice. No use, distribution or reproduction is permitted which does not comply with these terms. 


\section{APPENDIX}

Table A1 | Search strategy used for PubMed (from inception to September 2021).

\section{Search terms}

$\begin{array}{ll}\# 1 & \text { Epigallocatechin gallate OR epigallocatechin-3-gallate OR epigallocatechin-3-O-gallate OR "EGCG cpd" OR epigallo-catechin gallate } \\ \# 2 & \text { Quercetin[MeSH] } \\ \# 3 & \text { Genipin } \\ \# 4 & \text { Proanthocyanidins[MeSH] OR "condensed tannin" OR "anthocyanidin polymer" OR procyanidin* } \\ \# 5 & \text { Naringenin } \\ \# 6 & \text { Hesperidin[MeSH] OR "hesperetin } 7 \text { rhamnoglucoside" OR "hesperetin } 7 \text { rutinoside" } \\ \# 7 & \text { "Crosslinking agent*" OR "cross link" } \\ \# 8 & \text { Plant extracts[MeSH] } \\ \# 9 & \# 1 \text { OR \#2 OR \#3 OR \#4 OR \#5 OR \#6 OR \#7 OR \#8 } \\ \# 10 & \text { Dental cements[MeSH] OR "dental adhesive*" OR "luting agent" OR dentistry [MeSH] } \\ \# 11 & \text { Bond* AND strength } \\ \# 12 & \# 9 \text { AND \#10 AND \#11 }\end{array}$

